\title{
Laryngotracheoesophageal cleft type 3
}

INSERM

\section{Source}

INSERM. (1999). Orphanet: an online rare disease and orphan drug data base.

Laryngotracheoesophageal cleft type 3. ORPHA:93940

Laryngo-tracheo-esophageal cleft (LC) type 3 is a congenital respiratory tract anomaly characterized by a cleft extending through the cricoid cartilage, sometimes into the cervical trachea, with severe swallowing disorders, lung infections and pulmonary damage. 